\title{
Population dynamics model for plasmid bearing and plasmid lacking cells for streptokinase production in continuous flow stirred tank bioreactor
}

\author{
Pavan Kumar, Sanjoy Ghosh* \\ Computational Bioprocess Engineering Laboratory, Department of Biotechnology, Indian Institute of Technology Roorkee, Roorkee-247667, Uttarakhand, INDIA \\ *Corresponding author: e-mail: ghoshfbs@iitr.ernet.in, Tel: +91-1332-285424, Fax: +91-1332-273560
}

\begin{abstract}
Streptokinase production in bioreactor is well associated to cell population dynamics. It is an established fact that two types of cell populations are found to emerge from the initial pool of recombinant cell population. This phenomenon leads to an undesired loss in yield of the product. Primary metabolites, like acetic acid etc are formed as by-product of metabolism, has its influential role in regulating the competitive and inhibitory dynamics. Metabolites are found to play a crucial role since their threshold amount is assumed to promote the formation of plasmid lacking cells. On the other hand probability of plasmid loss has shown to follow a variable trend in the model dynamics. In this study a process model with coupled differential equations is designed to reveal the interaction among various parameters.
\end{abstract}

Keywords: streptokinase, bioreactor, primary metabolites, plasmid loss, computer simulation, model dynamics

\section{Introduction}

The bioreactor is often used to gather information in form of data, regarding the microorganism in order to generate a mathematical model utilizing a set of culture parameters. On the coexistence of two species which occurs in handling the recombinant cells population, an interaction occurs which may not be simply evaluated as of competitive type. The formation of product like streptokinase is directly related to the population of plasmid bearing cells which often having decreasing trend with respect to process duration due to plasmid instability. Various indispensable factors serve as significant parameter in this model. A threshold criterion is implemented for toxicity effect generated from primary metabolite for the growth of cells. Their effective concentration may bring mortality or sluggishness in growth, moreover it facilitates the cells to carry out and enhance the state of plasmid instability. Mortality is often considered to lower the extent of inter specific competition and thereby promote the coexistence of competing species (Abrams, 2001). Preferably our endeavour is to bring up a sophisticated model that has close resemblance to a natural chemostat in behaviour retaining the involved noticeable factors that seems to play some relevant role. Thus a computer model has been developed to investigate the bioprocess potential keeping a dynamic view into account.

\section{Early Population Dynamics Models}

One of the basic models for population dynamics was proposed earlier by Lotka and Volterra (Bailey and Ollis, 1986) which interprets the population interaction for a prey-predator like system. The dynamics is given by the relation,

$$
\begin{aligned}
& \frac{d A}{d t}=\alpha A-\beta A B \\
& \frac{d B}{d t}=-\gamma B+\delta A B
\end{aligned}
$$


Where, $\alpha$ growth rate of prey or population $\mathrm{A}, \beta$ rate at which predators or population $\mathrm{B}$, destroy prey, $\gamma$ death rate of population $\mathrm{B}$ and $\delta$ rate at which predators increase by consuming the prey. The above model Equations (1) and (2) has some relevance in bioprocess since chemostat adopts the behaviour of theoretical ecology. A microbial ecosystem was considered as a functional entity characterized by certain macroscopic measurements such as the total quantity of biomass or the total number of cells in the medium. It is possible to work with rapid growth of species in well controlled environments, such as "chemostat" (Harmand, 2008). During the culture and production of microorganisms, the control of the bioprocess sometimes depends on the microorganism concentration or the biomass density and conditions provided for that time period, for instance, in case some aerobic microorganisms the Dissolved Oxygen (DO) is a key factor to their growth (Guo and Chen, 2009).

Biochemically streptokinase, a well known fibrinolytic activator that enhances the conversion of plasminogen to the fibrinolytic enzyme plasmin. Workers have over-expressed the streptokinase in E.coli. It is $47 \mathrm{kDa}$ protein encoded by skc gene of Streptococcus equisimilis which is a gram positive bacterium. Though skc gene is known to have many rare codons in its composition, overexpression was achieved instead of having some negative effect. Earlier the constructs were transformed into BL21 (DE3) and grown in LB medium till 0.6 OD at A600. Then the cultures were induced with $1 \mathrm{mM}$ IPTG at $37 \mathrm{deg} \mathrm{C}$ for $3 \mathrm{~h}$. The expression profile of the streptokinase samples were analyzed (Thangadurai et al., 2008). The analysis of relative codon frequency of $s k c$ gene in E.coli reveals the presence few position specific rare codons that affect the heterologous protein expression significantly.

While performing fermentation process in the bioreactor, recombinant cells are found to lose their plasmid. After some time as the fermentation proceeds two types of cell populations are developed. Since substrate is a growth-limiting nutrient (or factor) so there starts a competition between two populations. The organisms carrying the plasmid or plasmid bearing cells are likely to be weaker competitors than one without because of the added load on its metabolic machinery (Lu and Hadeler, 1998).

There could be a number of factors that regulates the dynamics of plasmid carrying cells within the reactor. One such major factor is probability of plasmid loss due to segregation during cell division that can be described by segregative instability coefficient (Syamsu et al., 1992). On the other hand, the likelihood of segregation for a plasmid bearing cell is independent of the frequency of plasmid-free cells generation in the population (Lenski and Bouma, 1987) while the selection intensity against plasmid carriage is influenced by occurrence of plasmid lacking cells in population. In cell division process occasionally a daughter cell results that does not contain the plasmid and can no longer produce the desired product (Stephens et al., 1992). Plasmid free cells being faster in adapting to environmental changes, it is indeed possible to give a competitive edge to a plasmid containing population through cycling of dilution rate. But periodic variation of dilution rate noticeably proved to have insignificant role in improving the performance of biomass production in a continuous process (Szewczyk and Warsaw, 1991).

The probability of plasmid loss in selective medium and difference in specific growth rate between recombinant and plasmid free cells (Zabriskie and Arcuri, 1986) are affected by factors like genetic make-up of the host cells and the reactor operating parameters such as temperature, $\mathrm{pH}$ and growth medium composition. Moreover the selective pressure of selection medium is less effective due to the leakage of gene product (Sardonini and Dibiasio, 1987) which is responsible for selective mechanism.

A chemostat model of competition can be established between plasmid bearing and plasmid free organism for a single nutrient where plasmid bearing organism can produce toxin against plasmid free organism at same cost to its reproductive abilities (Hsu and Waltman, 2000). Lenski and Hattingh (1986) studied the effect of an inhibitor on two populations. They considered the degree of inhibition in presence of inhibitor or toxicant on growth rate. It is studied that estimation of unmeasurable biological variables is important in fermentation process, directly influencing the optimal control performance of the fermentation system as well as quality and yield of the targeted recombinant product, applying some novel strategy for state estimation of fed-batch fermentation (Jianlin et al., 2010).

The input substrate concentration and dilution rate serve as operating parameters and they are to be controlled by the experimenter. The study for the cases where nutrient supplied at constant rate and time dependent manner were performed earlier and a delay in the growth response of organism to nutrient uptake is obtained. Varying feed profiles were employed in the postinduction phase of recombinant streptokinase protein expression, including constant feed rates, linearly increasing feed rate and exponentially varying feed rates (Ramalingam et al., 2007) to evaluate the requirement of variable feed strategy. Modulation of an input such as a substrate or a nutrient concentration or the cell environment such as the $\mathrm{pH}$ can enhance the rates of biochemical reactions that are occurring (Silveston et al., 2008). A twofold increase in the concentration of plasmid bearing cells using square wave modulation of the dilution rate has been found. The use of altering dilution rate for the same environment setting can revert competitive exclusion to species coexistence (Costa and Meza, 2006).

According to model proposed by Imanaka and Aiba (1981) for a continuous culture the two types of population of cells, plasmid bearing and non bearing cells having interaction given by the following expression, Eqs. (3) and (4):

$$
\begin{aligned}
& \frac{d N_{1}}{d t}=\mu_{1} N_{1}-D N_{1}-p \mu_{1} N_{1} \\
& \frac{d N_{2}}{d t}=p \mu_{1} N_{1}+\mu_{2} N_{2}-D N_{2}
\end{aligned}
$$


Where, $N_{I}$ population of plasmid bearing cells and $N_{2}$ population of plasmid free cells. The above model Equations (3) and (4) considered, is purely of exploitative competition since no toxin is assumed to be formed. Another model was given by Stephanopaulis and Lapidus (1988) which is very close to the model given by T. Imanaka and S. Aiba, it includes three parameter variables plasmid bearing and plasmid lacking cell populations and substrate concentration which is limiting, expression shown in set of mass balance Eqs. (5) - (7):

$$
\begin{aligned}
& \frac{d X_{1}}{d t}=\mu_{1} X_{1}(1-q)-D X_{1} \\
& \frac{d X_{2}}{d t}=\mu_{2} X_{2}+q \mu_{1} X_{1}-D X_{2} \\
& \frac{d S}{d t}=D\left(S_{0}-S\right)-\frac{1}{Y}\left(\mu_{1} X_{1}-\mu_{2} X_{2}\right) \\
& S_{0} \geq 0, X_{i}(0)>0, i=1,2 .
\end{aligned}
$$

\section{New Model Assumptions}

In case selective media is considered, a relevant factor selection stress coefficient can be taken into account which is favourable for plasmid bearing cells (Sardonini and Dibiasio, 1987) while it does not favour the plasmid free cells. Since it favours the population of plasmid bearing cells so this parameter would be considered to resist the phenomenon of plasmid loss. Therefore probability of plasmid loss in selective medium is smaller than that in non-selective medium.

During the process of fermentation metabolites formation (Lee and Papoutsakis, 1999) occur as by-products of metabolism which are toxic (Stuebner et al., 1991) and inhibit the growth of both types of cells to different extent. The plasmid bearing cells are likely to lose their plasmid because of the permeability of such metabolites into the cells from the environment while other type that is free of plasmid do not have that much extent of harm. In other words we can say that toxicity of metabolite equally harm both the population simultaneously but since plasmid bearing cells are liable to lose their plasmid in response, so plasmid free cell population is strengthening in the same time. So plasmid free cell population or its specific gravity would have an increasing trend despite of decreasing due to this event.

The probability of plasmid loss is not constant throughout the fermentation process due to the formation of metabolites which shows its presumed toxic effect after certain threshold concentration, so it needs to be taken as variable parameter in the model with respect to time. A criterion of threshold policy can be implemented to evaluate collective probability factor which influence the time dependent variation in probability. Also mortality or formation of dormant cells is possible which is due to toxification developed on account of toxic metabolite or by-product formation, like acetic acid formation in case of fermentation process carried for streptokinase production. Therefore, considering the above assumptions we may write the dynamic model as:

$$
\begin{aligned}
& \frac{d X_{1}}{d t}=\mu_{1} X_{1}(1-q)-D X_{1}-m_{1} \mu_{1} X_{1}+r_{1} \mu_{1} X_{1} \\
& \frac{d X_{2}}{d t}=\mu_{2} X_{2}+q \mu_{1} X_{1}-D X_{2}+m_{1} \mu_{1} X_{1}-m_{2} \mu_{2} X_{2}-r_{1} \mu_{1} X_{1} \\
& \frac{d S}{d t}=D\left(S_{0}-S\right)-\frac{1}{Y}\left(\mu_{1} X_{1}+\mu_{2} X_{2}\right) \\
& \frac{d q}{d t}=\left(1-e^{-m f\left(\frac{X_{2}}{X_{1}+X_{2}}\right)}\right) \mu_{2} \\
& \frac{d M}{d t}=Y M^{\left(X_{1} \mu_{1}+X_{2} \mu_{2}\right)-D M}
\end{aligned}
$$




$$
\begin{aligned}
& \frac{d P}{d t}=Y_{P}\left(\mu-q k_{d}\right) X_{1}-P\left(k_{P}-D\right) \\
& \mu_{1}=\frac{\mu_{1 m a x} S}{\left(K_{1}+S\right)} \\
& \mu_{2}=\frac{\mu_{2 m a x} S}{\left(K_{2}+S\right)} \\
& f_{1}=m_{P}-r+z \\
& f_{2}=z-r \\
& \text { where, } m_{f}=\left\{\begin{array}{l}
f_{1} \text { if } M>M_{t h} \\
f_{2} \text { if } M<M_{t h}
\end{array}\right.
\end{aligned}
$$

Here, $m_{1}>m_{2}$

also, $\left(0<f_{1}, f_{2}<1\right)$

Since metabolic toxicity has an influence over plasmid bearing cell population to a larger amount.

$m_{1} \& m_{2}=0$, if $M<M_{t h}$

$M_{\text {th }}$ required to be evaluated for different recombinant strain of micro-organisms and media composition under varying set of operational conditions and it depends upon experimental setup with presumed parameters for a bioprocess. Likewise, values of constants $m_{l}, m_{2}, m_{p}$ and $r_{l}$ could be assessed for a defined set of conditions.

The dynamics related to plasmid bearing and lacking cell populations together with effects impart due to metabolite toxicity and selective stress has been shown in mass balance Eqs. (8) and (9). Material balance for substrate concentration is expressed in Eq. (10) where the substrate consumption rates are considered proportional to the rates of formation of the two types of cells through their yield factors. The kinetics shown in Equations (11) and (12) ensures the role of varying probability of plasmid loss in the model and variation in metabolite concentration respectively. The Eq. (13) is mass balance for product i.e., streptokinase formation, Eqs. (14) and (15) are Monod expressions to compute specific growth rates. For the collective probability factor $m_{f}$ two variants are used as $f_{l}$ and $f_{2}$, in expression (16) and (17) that has got variable net probability tested with the level of threshold metabolite concentration to assume its value.

Since initially plasmid lacking cell population and metabolite concentration is absent in the medium, both can be taken to zero. In the very start of the process all cells present are plasmid bearing, so the probability of plasmid loss is also to be taken as zero. The magnitude of recombinant cell population and substrate has a pivotal role in governing the dynamics.

\section{Results and Discussion}

The simulation of the above model is done using Matlab 7.2. The initial values (Patnaik, 1995) taken for different parameters at time zero has been shown in Table 1 .

Table 1: Initial values of model variables:

\begin{tabular}{llc}
\hline Variable & Unit & Initial Value \\
\hline$X_{1}$ & $\mathrm{~g}^{-1}$ & 0.70 \\
$X_{2}$ & $\mathrm{~g}^{-1}$ & 0.00 \\
$S$ & $\mathrm{~g} \mathrm{l}^{-1}$ & 70.00 \\
$M$ & $\mathrm{~g} \mathrm{l}^{-1}$ & 0.00 \\
$q$ & - & 0.00 \\
\hline
\end{tabular}


The simulation is done using most of the standard values taken from a previous model data meant for streptokinase (Patnaik, 2002) together with various other model constraints with smaller magnitude assumed for different set parameters which have been given in Table 2, taken on the basis of their apparent role in this dynamical system. The probability of plasmid loss is zero at time $\mathrm{t}_{0}$ since at the beginning of process all recombinants cells have plasmid machinery.

Table 2: Values of parameters assumed in the model:

\begin{tabular}{lll}
\hline Variable & Unit & Initial Value \\
\hline$S_{0}$ & $\mathrm{~g}^{-1}$ & 70.00 \\
$\mu_{I \max }$ & $\mathrm{h}^{-1}$ & 0.74 \\
$\mu_{2 \max }$ & $\mathrm{h}^{-1}$ & 0.80 \\
$Y$ & - & 2.00 \\
$Y_{M}$ & - & 4.80 \\
$\mathrm{Y}_{\mathrm{P}}$ & - & 0.44 \\
$k_{d}$ & $\mathrm{~h}^{-1}$ & 0.02 \\
$k_{p}$ & $\mathrm{~h}^{-1}$ & 0.0005 \\
$K_{l}$ & $\mathrm{gl}^{-1}$ & 20.00 \\
$K_{2}$ & $\mathrm{~g}^{-1}$ & 10.00 \\
$m_{1}$ & - & 0.08 \\
$m_{2}$ & - & 0.003 \\
$m_{p}$ & - & 0.010 \\
$r$ & - & 0.01 \\
$r_{l}$ & - & 0.02 \\
$z$ & - & 0.001 \\
\hline
\end{tabular}

Different dilution rates are considered which proved to be the most relevant factor for continuous operation. Dilution rate was started at a very low value and increased to high values to evaluate the sensitivity of response at different levels.

Specific growth rates taken for plasmid bearing and plasmid lacking cells in the model are different since specific growth rate of plasmid lacking cells are noticeably higher. Yield factor which is regarded to be the ratio of gram of cells formed and gram of substrate consumed is taken together with another yield term associated to the formation of metabolite. Other constants governing the effect of metabolite concentration are the two toxicity coefficients $m_{l}$ and $m_{2}$. While various model related probability factors are effectively incorporated pertaining to plasmid loss due to metabolite toxicity and plasmid retention for selective stress, some other rare factors are also considered.

The approximate value of exponential term is taken $e=2.71828$, as the base of natural logarithm. The value of threshold concentration of metabolite taken here, $m_{t h}=0.75$, which has its pronounced key role in leading the major aspects of the process. Additionally another factor, selection stress coefficient is incorporated to strengthen the model in respect to the selective operation carried over by traces of antibiotics present in the medium. The stress causing substances present in the environment which inhibits the formation of cells devoid of any plasmid. The simulation is done at low and a fairly high different dilution rate viz. $D_{I}$ and $D_{2}$, as being shown in subsequent plots. In figures all three variables with different initial value (table 1) are taken together to generate the dynamics. The cases having dilution going outside the limit i.e., $0.23 \leq D_{i} \leq 0.52, \mathrm{i}=1,2, \ldots$; have not been studied because of insignificant changes beyond the range for this context. The model plot for three vital variable parameters are simulated, the uppermost prominant dashed line showing $X_{I}$ and the just lower solid line is representing $X_{2}$, the third dash-dot line is showing product (streptokinase) concentration. Plotting all the three variable parameters in Figs. (1) and (2), together consequently justifies the correlation among different component variables simultaneously.

It is quite reasonable to investigate that low dilution rate allows the fermentation to last longer generates higher magnitude of concentration of plasmid bearing cells and favour the consumption of substrate. The numerical simulation of the model equations shows plasmid loss tends to occur after a certain limit of metabolite level, which depicts that the increasing concentration of metabolite tends to support the population of plasmid lacking cells that witnesses the trend in loss of plasmid from recombinant cells. Using the simulation dynamics it becomes easier to resolve the plot in order to understand the trend followed by the two population of cells. The probability of plasmid loss has its dependence over metabolite concentration and the two population of cells. The varying probability has its impact over the dynamics of the model thereby involving almost all the parameters that are being substantially effected due to its variability. It is very interesting to note that only a threshold amount of metabolite concentration is responsible for starting the variable dynamics of plasmid lacking and plasmid bearing cells. The model simulation is done using most of the standard values from existing models and assumed constraints required to explicate this dynamical system. 


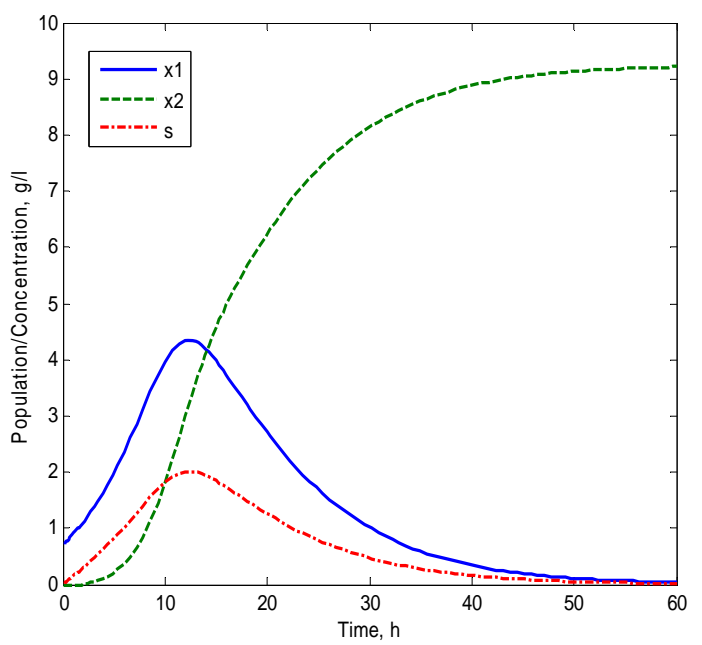

Fig 1: Dynamics shown in plot at dilution rate, $D_{2}=0.23$

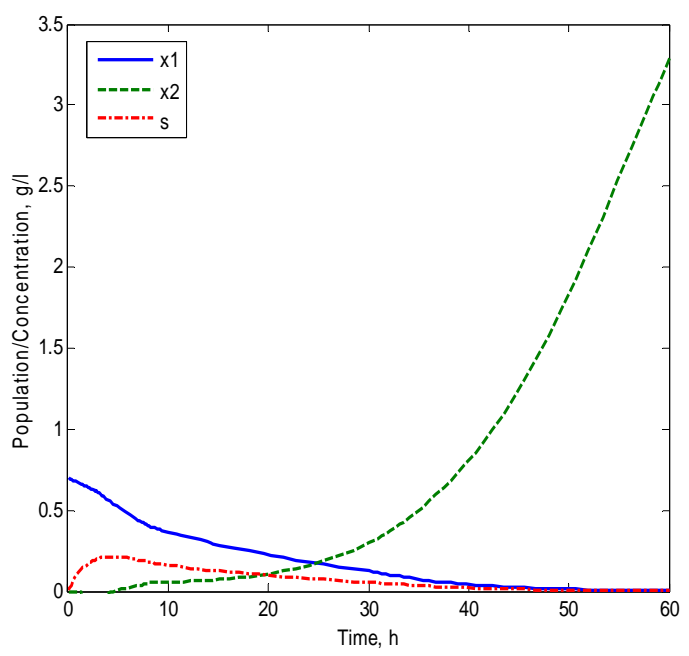

Fig 2: Dynamics shown in plot at dilution rate, $D_{5}=0.52$

Dynamics observed in initial plots, Fig. 1, clearly depicts the bifurcation in population of pure recombinant cells and growth in plasmid lacking cell population. Noticeable decline in $X_{1}$ with subsequent elevation in $X_{2}$ level is evident on moving from Fig. 1 to 2. After a certain dilution rate the downward steepness of the the curve elucidate the event of ongoing increase in plasmid lacking cells, indicates that there is a gradual decline in the level of recombinant cells on enhancing the dilution, shown in Figs. 2. Since the production of streptokinase is directly depending upon the dynamics of palsmid bearing cells so to enhance the production it is inevitable to reveal the kinetics operating factors and to evaluate the instability of the plasmid. The rise in probability can also be well marked in the plots in respect to the remarkable hike in metabolite formation. These two events can be supposed to deduce the trend followed by growth of plasmid lacking cell population.

The influence of dilution rate $D$ on concentration of plasmid bearing and plasmid lacking cells with respect to time duration of continuous process is represented in two plots, Fig. 3 and 4.

The plots in respect to dilution rate have their importance in deciphering the behavior of biased inter-population cell dynamics in this case. The results emphasizes that delayed plasmid loss occurs at lower dilution rates. Numerical simulation of the continuous fermentation process could be rather helpful to enhance the performance adjusting dilution rate to achieve product in amplified amount.

The observed trends are matched by the concentration profiles at different time duration of the fermentation process. It could be noted that better dynamics is obtained at late hours. Two cases are studied for plasmid bearing and plasmid lacking cells. The concentration profile is plotted at duration in hours: 15, 30, 45 and 60, for $X_{1}$ and $X_{2}$ cell concentrations, Figs. 3 and 4 respectively. There is a remarkable increase in abruptness of the slope on progressing ahead in respect to process duration, from $60 \mathrm{hrs}-15 \mathrm{hrs}$. Fig 3, showing nearly smooth variation with increasing duration on the other hand irregular variability is there with respect to concentration in Fig. 4. An interesting feature reflected by plotting concentration against dilution rate is assessment of time in 
governing the interaction between cell populations $\left(X_{1}\right.$ and $\left.X_{2}\right)$ and dilution rate regardless of how intense the phenomena associated to other variables are progressing.

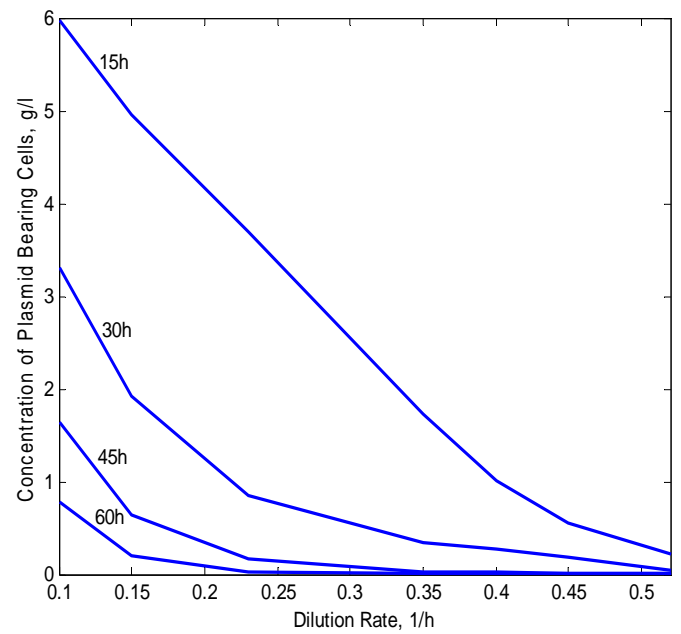

Fig 3: Effect of dilution rate on plasmid bearing cells with respect to time duration of fermentation process

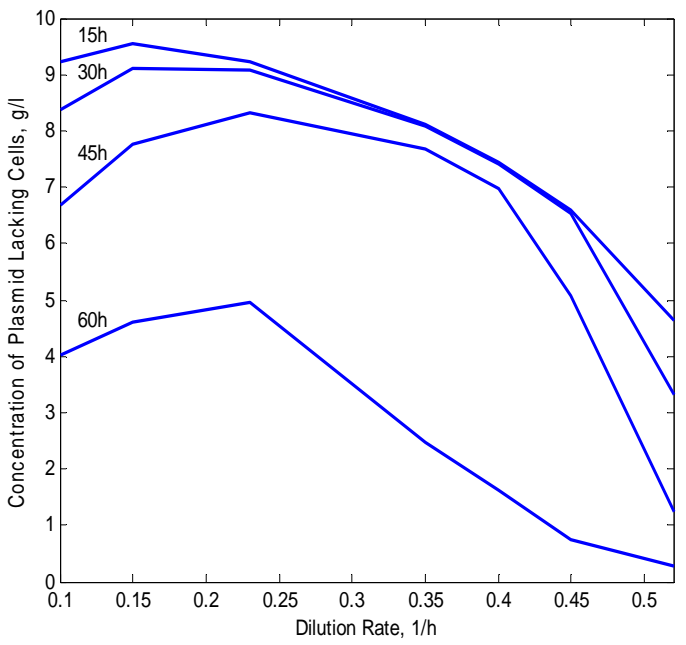

Fig 4: Effect of dilution rate on plasmid lacking cells against time duration

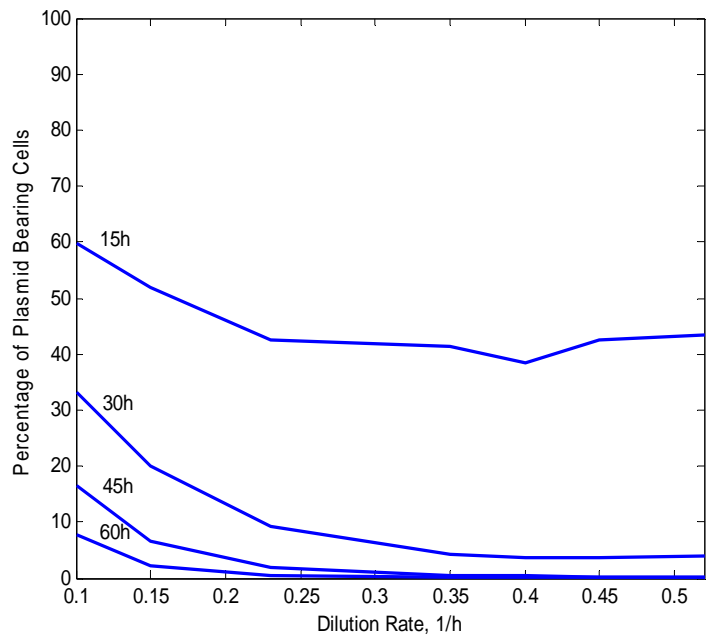

Fig 5: Effect of dilution rate on percentage of plasmid bearing cells with respect to time duration 
Fig. 5 shows the effect of dilution rate on percentage of plasmid bearing cells with respect to time duration. An interesting feature of changing probability of plasmid loss with respect to metabolite concentration at different dilution rates, is depicted in Fig. 6. There is a very high probability of plasmid loss even at low metabolite concentration on moving towards a high dilution rate. Particularly the probability has shown a rapid hike on increasing dilution rate from $D=0.45$ to $D=0.52$. The percentage of plasmid bearing cells with respect to time in Fig. 7, showing a gradual decreasing trend on increasing the dilution rate to some extent, $D=0.35$, the declining trend is not found to exist on further dilution rates.

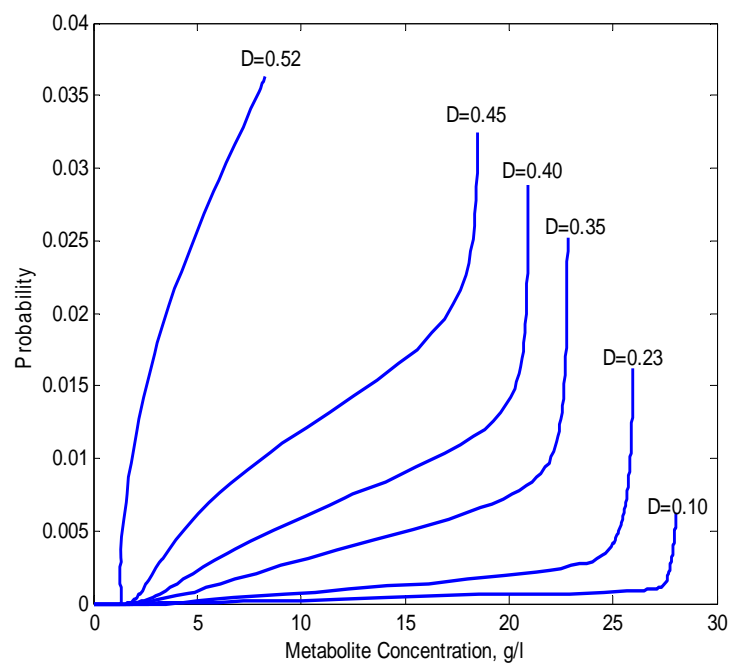

Fig 6: Changing probability of plasmid loss with respect to metabolite concentration at different dilution rates

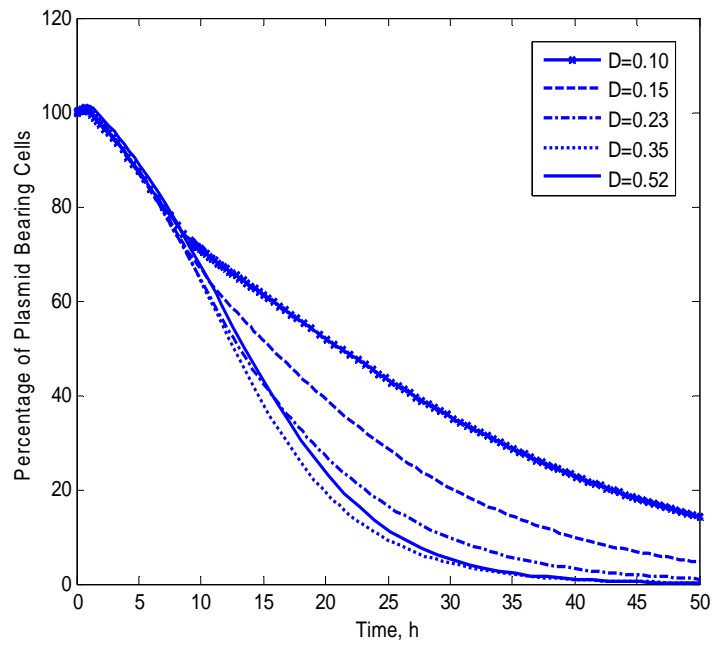

Fig 7: Percentage of plasmid bearing cells with respect to time

\section{Conclusions}

The behaviour of the systems like bioreactor is found to be solely dynamic. Population dynamics model for plasmid bearing and plasmid lacking cells in bioreactor has been made more robust to develop an insilico dynamical system which has the characteristics of a chemostat that we used to employ for streptokinase production. The representation of the dynamical system through modelling has its relevance in predicting the behaviour of the system on disturbances or changes made in initial conditions.

The five parameters, including plasmid bearing cell population, plasmid lacking cell population, substrate concentration, metabolite concentration and probability of plasmid loss are taken into account. The idea is to measure the instability of plasmid which can be directly derived from the growth of plasmid lacking cell population. The model has been simulated at different dilution rates and different initial substrate concentration and thereby differences in the model behaviour have been observed on simulation. There is a remarkable decline in the percentage of plasmid bearing cells above a certain level of dilution rate. System 
has shown its prevalent sensitivity to change in dilution rate. The probability of plasmid loss has shown a gradual trend at high dilution rates. In the proposed model new factors are taken into account like selection stress coefficient and metabolite toxicity coefficient that have resolved the simultaneous variation in other parameters and their interaction criteria. Selection stress coefficient shows to resist the process of plasmid loss up to some extent. Increasing concentration of metabolites has shown to inhibit the growth of two cell populations after attaining a certain threshold concentration, it leads to the fact that plasmid lacking cells population has adopted an increasing trend while plasmid bearing cell population is found to follow a decreasing trend. The most significant consideration of the model is the changing probability of plasmid loss with respect to time which incorporates the effect generated from toxicity developed by the metabolites. Various other time invariants and intrinsic constraints are together taken into account to plot their collective effect with probability factor. The model ensures a higher degree of flexibility since it has a number of adjustable parameters. Still efforts regarding validation of the model using heuristic approaches to impart certain non-ideal bioreactor conditions is underway.

\section{Nomenclature}

$X_{1}, X_{2} \quad$ Concentration of two cell populations (g/l) $X_{I}$-plasmid bearing, $X_{2}$-plasmid lacking cells

$Y \quad$ Yield i.e., ratio of gram of cells formed and gram of substrate consumed

$Y_{M} \quad$ Yield in terms of metabolite

$M_{\text {th }} \quad$ Threshold concentration of metabolite that can effect population growth (g/l)

$m_{l} \quad$ Metabolite toxicity coefficient for plasmid bearing cells

$m_{2} \quad$ Metabolite toxicity coefficient for plasmid free cells

$r_{1} \quad$ Selection stress coefficient

$M \quad$ Metabolite concentration $(\mathrm{g} / \mathrm{l})$

$m_{f} \quad$ Collective probability factor

$m_{p} \quad$ Probability factor associated to metabolite toxicity

$r \quad$ probability of plasmid retention due to selective stress

$z \quad$ Probability of plasmid loss due to other structural or rare factors

$p \quad$ Probability of plasmid loss

$K_{l} \quad$ Monod coefficient for plasmid bearing cells (g/l)

$K_{2} \quad$ Monod coefficient for plasmid lacking cells $(\mathrm{g} / \mathrm{l})$

$k_{d} \quad$ Decay constant for plasmid bearing cells $(1 / \mathrm{h})$

$k_{p} \quad$ Decay constant for product $(1 / \mathrm{h})$

$D \quad$ Dilution rate or washout rate $(1 / \mathrm{h})$

$q \quad$ Probability of plasmid loss

$S_{0} \quad$ Initial substrate concentration $(\mathrm{g} / \mathrm{l})$

$\mu_{1} \quad$ Specific growth rate of plasmid bearing cells $(1 / \mathrm{h})$

$\mu_{2} \quad$ Specific growth rate of plasmid free cells $(1 / \mathrm{h})$

$\mu_{\operatorname{lmax}} \quad$ Maximum specific growth rate of plasmid bearing cells $(1 / \mathrm{h})$

$\mu_{2 \max } \quad$ Maximum specific growth rate of plasmid free cells $(1 / \mathrm{h})$

\section{Acknowledgment}

The authors thankfully acknowledge the financial help received from Department of Biotechnology, Ministry of Science of Technology, Govt. of India in from of project grant (No. BT/PR4676/BID/07/072/2004).

\section{References}

Abrams. P., 2001. The effect of density-independent mortality on the coexistence of exploitative competitors for renewing resources, American Naturalist, Vol. 158, No. 5, pp. 459-470.

Bailey J.E. and Ollis D.F., 1986. Biochemical engineering fundamentals, Mc Graw-Hill Book Co., New York, Vol. 4, pp. 79-108.

Costa M.I.S. and Meza M.E.M., 2006. Coexistance in a chemostat: Application of a threshold policy, Chemical Engineering Science, Vol. 61, pp. 3400-3402.

Guo H. and Chen L., 2009. Periodic solution of a chemostat model with Monod growth rate and impulsive state feedback control, Journal of Theoretical Biology, Vol. 260, pp. 502-509.

Harmand J., Rapaport A., Dochain D. and Lobry C., 2008. Microbial ecology and bioprocess control: Opportunities and challenges. Journal of Process Control, Vol. 18, pp. 865-875.

Hsu S.B. and Waltman P., 2000. A model of the effect of anti-competitor toxins on plasmid- bearing, plasmid free competition, Taiwanese Journal of Mathematics, Vol. 6, No.1, 135-155. 
Imanaka T. and Aiba S., 1981. A perspective on the application of genetic engineering: Stability of recombinant plasmid, Ann. $N$. Y. Acad. Sci., Vol. 369, pp. 1-14.

Jianlin W., Liqiang Z. and Tao Y., 2010. On-line estimation in fed-batch fermentation process using state space model and unscented kalman filter, Chinese Journal of Chemical Engineering, Vol. 18, No. 2, pp. 258-264.

Lee S.Y. and Papoutsakis E.T., 1999. Metabolic Engineering, Marcel-Dekker, USA, Vol. 2, pp. 13-58.

Lenski R.E. and Bouma J.E., 1987. Effects of segregation and selection on instability of plasmid pACYC184 in Escherichia coli, Journal of Bacteriology, Vol. 169, pp. 5314-5316.

Lenski R.E. and Hattingh S., 1986. Coexistance of two competitors on one resource and one inhibitor: A chemostat model based on bacteria antibiotics, J. Theor. Bio., Vol.122, pp. 83-93.

Lu. Z. and Hadeler. K.P., 1998. Model of plasmid-bearing, plasmid- free competition in the chemostat with nutrient recycling and an inhibitor, Mathematical Bioscience, Vol. 148, pp. 147-159.

Patnaik P.R., 1995. A heuristic approach to fed-batch optimization of streptokinase production, Bioprocess Engineering, Vol.13, pp. 109-112.

Patnaik P.R., 2002. Neural optimization of fed-batch streptokinase fermentation in a non-ideal bioreactor, The Canadian Journal of Chemical Engineering, Vol.80, pp. 920-926.

Ramalingama S., Gautama P., Mukherjee K.J. and Jayaraman G., 2007. Effects of post-induction feed strategies on secretory production of recombinant streptokinase in Escherichia coli. Biochemical Engineering Journal, Vol. 33, pp. 34-41.

Sardonini C.A. and Dibiasio D., 1987. Biotechnology Bioengineering, Vol. 29, pp. 469-475.

Silveston P.L., Budman H. and Jervis E., 2008. Forced modulation of biological processes: A review Chemical Engineering Science, Vol. 63, pp. 5089 -- 5105

Stephanopaulis G. and Lapidus G., 1988. Chemostat dynamics of plasmid-bearing plasmid-free mixed recombinant cultures, Chem. Engineering Science, Vol. 43 49-57.

Stephens, M.L., Christensen C. and Lyberatos. G., 1992. Plasmid stabilization of an Escherichia coli culture through cycling, Biotechnol. Prog. Vol. 8, pp. 1-4.

Stuebner K., Boschke E., Wolfe K.H. and Langer J. 1991. Kinetic analysis and modelling of streptokinase fermentation, Acta Biotechnol, Vol. 11, pp. 467-77.

Syamsu. K., Impoolsup. A., Greenfield P.F. and Mitchell D.A., 1992. Data analysis of plasmid stability in continuous culture of recombinant Saccharomyces cerevisiae, Biotechnology Techniques, Vol. 6, No. 5, pp. 393-398.

Szewczyk, K.W. and Warsaw, 1991. The effect of dilution rate variation on the performance of continuous fermentation, Bioprocess Engineering, Vol. 6, pp. 17-19.

Thangadurai C., Suthakaran P., Barfal P., Anandaraj B., Pradhan S.N., Boneya H.K., Ramalingam S. and Murugan V., 2008. Rare codon priority and its position specificity at the 50 of the gene modulates heterologous protein expression in Escherichia coli, Biochemical and Biophysical Research Communications. Vol. 376, pp. 647-652.

Zabriskie D. and Arcuri E.J., 1986. Factors influencing productivity of fermentations employing recombinant micro-organisms, Enz. Microb. Technol., Vol. 8, pp. 706-717.

\section{Biographical notes}

Pavan Kumar obtained M.Tech degree from Indian Institute of Information Technology Allahabad (U.P.) India, in 2007. Presently he is pursuing his Ph.D from Indian Institute of Technology Roorkee (Uttarakhand) India, in the area of computational bioprocess engineering. His prime research interest is associated to modelling and simulation of streptokinase production and analysis of various parameters related to bioreactor operation.

Sanjoy Ghosh obtained Ph.D. degree from Department of Chemical Engineering, Indian Institute of Technology Madras, Chennai 600036, India in the year 2002 with specialization in Biochemical Engineering. Subsequently, he worked as Assistant Professor in Centre for Biotechnology, Anna University, Chennai, India, currently he is Assistant Professor in the Department of Biotechnology, Indian Institute of Technology Roorkee, Roorkee, Uttarakhand, India since 2006. His main research interest include, bioethanol production from lignocellulosic material, enzyme technology, mathematical modelling of biorprocess, bioprocess development etc.

Received April 2009

Accepted May 2010

Final acceptance in revised form June 2010 